\title{
A Lei Cidade Limpa e a regulação da poluição visual na cidade de São Paulo
}

\author{
Clean City Law and regulation of visual pollution in the city of São Paulo
}

Fábio Nogueira Barros ${ }^{1}$

\begin{abstract}
1 Mestrando em Direito na Universidade Nove de Julho na linha de pesquisa de Sustentabilidade e Empresa. Bacharel do curso de Direito na Universidade Federal de Alagoas. E-mail: fabio.n.barros@globo.com
\end{abstract}

RESUMO: O presente artigo se propõe a analisar a Lei Cidade Limpa do município de São Paulo. Ela limita o excesso publicitário físico dentro da cidade, uma virtude vinda das diretrizes constitucionalmente estabelecidas para a dignidade humana dentro do meio ambiente artificial. O foco se destina à visão dos seus artigos, além das fontes normativas na Constituição Federal, e contextualiza a razão da existência desta lei: salvaguardar o direito fundamental ao meio ambiente equilibrado. O método utilizado foi o bibliográfico dedutivo e a conclusão é que a Lei é excessivamente restritiva, mas benéfica ao tornar o ambiente urbano mais visualmente agradável.

Palavras-chave: Meio Ambiente Artificial, Poluição Visual, Direito Ambiental, Direito Urbanístico, Direito Constitucional.

ABSTRACT: The present article proposes to analyze São Paulo's Clean City Law. It limits the excesses of physical advertising within the city, a virtue from the constitutionally established guidelines for human dignity within the artificial environment. The focus is on the vision of its articles, besides the normative sources in the Federal Constitution, and contextualizes the reason for this law's existence: to safeguard the fundamental right to the balanced environment. Deductive bibliography was the method used and the conclusion is that the law is excessively restrictive, but beneficial in making the urban environment more visually pleasing.

Keywords: Artificial Environment, Visual Pollution, Environmental Law, Urban Law, Constitutional Law.

SUMÁRIO: Introdução - 1 O Meio Ambiente Artificial - A Cidade - 2 A Poluição Visual - 3 A Lei Cidade Limpa Considerações Finais - Referências

\section{INTRODUÇÃO}

A cidade de São Paulo, com seus $1.521,110 \mathrm{~km}^{2}$ de área e 12.176 .866 habitantes estimados no ano de 2018 (IBGE, 2018), é a maior cidade do hemisfério sul e um dos maiores centros comerciais e culturais do planeta. Devido à sua enorme população e ao seu perfil de metrópole, a cidade teve, por muito tempo, problemas relacionados à excessiva publicidade espalhada por seu espaço urbano. O seu meio ambiente tornou-se, desta forma, vítima dos excessos desregulados, ou regulados com muita flexibilidade, dos setores de publicidade e propaganda do comércio local, nacional e internacional.

A história humana pode ser, também, chamada de história da urbanização. O aumento dramático no tamanho da população urbana durante o século XX influenciou diretamente os aspectos territoriais, climáticos e estruturais dos locais onde as cidades se erguem. A harmonia necessária para manutenção destes locais se compõe de vários fatores complexos (SANTAMOURIS, 2013).

A proteção dos habitantes de uma cidade é atribuição do governo local, e o governo da cidade de São Paulo, tendo em vista exatamente o crescente descontrole na condição visual dos logradouros urbanos, 
publicou a Lei Municipal n 14.233/2006, também conhecida como Lei Cidade Limpa, para regular a correta utilização do espaço urbano no tocante à sua aparência estética (FIORILLO, 2017), ou, como explicitado em sua ementa, "dispõe sobre a ordenação dos elementos que compõem a paisagem urbana do município de São Paulo” (SÃO PAULO, Lei no 14.223/2006, Ementa).

O conceito de qualidade visual é diretamente ligado ao nível de ordem nos elementos existentes num espaço artificialmente construído. $\mathrm{O}$ aspecto de qualidade estética de algum ambiente se reflete positivamente tanto maior for a sua ordem, simetria e regularidade. O contrário disto, normalmente refletido pela exposição a peças publicitárias destoantes e à existência de espaços públicos desordenados provocam saturação nos indivíduos que coexistem naquele ambiente (PORTELLA, 2016).

O presente trabalho tem por objetivo percorrer, pelo método bibliográfico, a Lei Municipal 14.233/2006, além de estabelecer a conceituação teórica dos motivos para o qual esta Lei é um grande avanço na salvaguarda do direito fundamental ao meio ambiente equilibrado. Abordar-se-á, também, o conceito de poluição visual, de meio ambiente artificial e das razões pelas quais aquela é uma violação dos preceitos constitucionais envolvidos neste.

\section{MEIO AMBIENTE ARTIFICIAL - A CIDADE}

O ambiente artificial pode ser entendido como o espaço construído, e os equipamentos públicos urbanos, são os principais representantes deste ambiente. Neste sentido, o conceito de meio ambiente artificial apresentado neste artigo se deriva diretamente de FIORILLO (2017). Este autor afirma que

[...] o meio ambiente artificial é compreendido pelo espaço urbano construído, consistente no conjunto de edificações (chamado de espaço urbano fechado), e pelos equipamentos públicos (espaço urbano aberto). Dessa forma, todo o espaço construído, bem como todos os espaços habitáveis pelo homem compõem o meio ambiente artificial (FIORILLO, 2017, p. 607).

Para Fiorillo (2017) a cidade, como parte do meio ambiente artificial, recebe, por meio da Constituição da República Federativa do Brasil (CRFB) de 1988, tutela referente à necessidade de se adaptar a uma sociedade capitalista de matriz social, definida nos artigos. $1^{\circ}$ e 170 e seus incisos, dá-se especial atenção às dinâmicas emergentes da salvaguarda dos direitos fundamentais enumerados nesta Constituição, ao mesmo tempo em que se procura o desenvolvimento econômico pleno e livre, típico do sistema adotado, como pode ser observado em vários incisos dos artigos. $1^{\circ}$ e 170.

Art. $1^{\circ}$ A República Federativa do Brasil, formada pela união indissolúvel dos Estados e Municípios e do Distrito Federal, constitui-se em Estado Democrático de Direito e tem como fundamentos:

$[\ldots]$

III - a dignidade da pessoa humana;

IV - os valores sociais do trabalho e da livre iniciativa;

[...]

Art. 170. A ordem econômica, fundada na valorização do trabalho humano e na livre iniciativa, tem por fim assegurar a todos existência digna, conforme os ditames da justiça social, observados os seguintes princípios:

I - soberania nacional;

II - propriedade privada;

III - função social da propriedade;

IV - livre concorrência; 
$\mathrm{V}$ - defesa do consumidor;

VI - defesa do meio ambiente, inclusive mediante tratamento diferenciado conforme o impacto ambiental dos produtos e serviços e de seus processos de elaboração e prestação;

VII - redução das desigualdades regionais e sociais;

VIII - busca do pleno emprego;

IX - tratamento favorecido para as empresas de pequeno porte constituídas sob as leis brasileiras e que tenham sua sede e administração no País (BRASIL, CRFB/1988, arts. $1^{\circ}$ e 170).

A própria CRFB de 1988 em variados artigos e incisos (exemplo: 5, XXIII; 21, XX e 182), atenta para a solidificação da cidade como ente constitucionalmente protegido, proteção esta que ecoa diretamente nos aspectos de garantia dos direitos fundamentais da população, que só se atingem ao se proteger devidamente o local onde a maioria da sociedade desenvolve sua existência (FIORILLO, 2017), são exemplos os seguinte artigos:

Art. $5^{\circ}$ Todos são iguais perante a lei, sem distinção de qualquer natureza, garantindo-se aos brasileiros e aos estrangeiros residentes no País a inviolabilidade do direito à vida, à liberdade, à igualdade, à segurança e à propriedade, nos termos seguintes:

$[\ldots]$

XXIII - a propriedade atenderá a sua função social;

$[\ldots]$

Art. 21. Compete à União:

XX - instituir diretrizes para o desenvolvimento urbano, inclusive habitação, saneamento básico e transportes urbanos;

$[\cdots]$

Art. 182. A política de desenvolvimento urbano, executada pelo Poder Público municipal, conforme diretrizes gerais fixadas em lei, tem por objetivo ordenar o pleno desenvolvimento das funções sociais da cidade e garantir o bem-estar de seus habitantes (BRASIL, CRFB/1988, arts. 5º 21 e 182).

A formação das cidades vem da solução de três grandes problemas essenciais para a corrente organização populacional humana: (1) a mobilidade dos habitantes para os recursos disponíveis, (2) a manipulação e otimização do ecossistema para maior eficiência e produção de gêneros alimentícios e (3) a complexidade das relações sociais que emerge e guia a expansão e diversificação das atividades necessárias à manutenção destes núcleos (ELMQVIST et. al., 2013).

A introdução da agricultura, há pelo menos dez mil anos, permitiu ao ser humano se desvencilhar do seu então ciclo de procura nômade por recursos naturais. Isto solucionou o problema da otimização do ecossistema e possibilitou a criação de áreas povoadas perenemente, além de extinguir a necessidade de mobilidade permanente para os recursos disponíveis, dado que estes começaram a ser cultivados localmente de maneira fixa (ELMQVIST et. al., 2013).

O problema da complexidade das relações humanas que se desenvolve a partir da prevalência e aumento dos povoados começou a se resolver pela chamada Revolução Urbana, ocorrida originalmente na Mesopotâmia. De povoados fixos criados por grupos de caçadores e coletores, em relativamente pouco tempo houve a evolução destes locais para cidades, que se associaram em uma única civilização e desenvolveram os traços hoje associados com a evolução humana, como infraestrutura interurbana, economia, arquitetura e escrita, além da especialização do trabalho e consequente solidificação de um contexto social que se segue, com as devidas proporções, até a contemporaneidade (ELMQVIST et. al., 2013).

A criação das cidades, vindas diretamente da abertura, especialização e evolução econômica dos diferentes locais de agricultura, se é notada a partir de alguns fatores, como que defende Elmqvist et. al., (2013) 
ao afirmar que "[...] a large population that aggregates in a central location with buildings and monuments that represent institutions that organize and facilitate productivity"1 (ELMQVIST et. al., 2013, p. 89).

Estes locais são o produto físicos de variados fatores ambientais, sociais e econômicos fortemente relacionados às necessidades e padrões da sociedade. $\mathrm{O}$ ambiente urbano se molda das pressões econômicas e é influenciado pelos mercados de trabalho e de imóveis, pelos aspectos sociais de cultura, segurança, serviços básicos, identidade e acessibilidade, além das influências ambientais relacionadas ao uso da terra, da energia e dos materiais (SANTAMOURIS, 2013).

Analisar estes parâmetros não é uma tarefa a ser feita de forma isolada, mas de maneira integrativa, dada as interrelações extremamente complexas que a economia, a sociedade e o ambiente de uma cidade promovem para sua própria existência, como o clima modificado e a superfície adaptada ao ser humano, dentre outros fatores (SANTAMOURIS, 2013).

O equilíbrio e harmonia entre o desenvolvimento do comércio como atividade em centros urbanos e o bem-estar da população destes mesmos locais é objeto de legislações. Os elementos da paisagem urbana se adaptam às localidades em que eles ocorrem (PORTELA, 2013). No caso do município de São Paulo, tem-se, no artigo $2^{\circ}$ da Lei no $14.223 / 2006$, a sua definição:

Art. $2^{\circ}$. Para fins de aplicação desta lei, considera-se paisagem urbana o espaço aéreo e a superfície externa de qualquer elemento natural ou construído, tais como água, fauna, flora, construções, edifícios, anteparos, superfícies aparentes de equipamentos de infra-estrutura, de segurança e de veículos automotores, anúncios de qualquer natureza, elementos de sinalização urbana, equipamentos de informação e comodidade pública e logradouros públicos, visíveis por qualquer observador situado em áreas de uso comum do povo (SÃO PAULO, Lei no 14.223/2006, art. $2^{\circ}$ ).

Dentre as diversas limitações implementadas neste balanço entre o Estado e o Mercado, encontrase a necessidade de se proteger o bem-estar da população nas cidades. Nesta seara se encontra, dentre vários outros, o conflito referente à poluição visual dentro do ambiente urbano (FIORILLO, 2017). Este tipo de poluição se acopla às outras existentes que interferem no correto funcionamento da cidade conforme a CRFB de 1988, como sendo a poluição atmosférica, sonora, fluvial, todas formas mais abertamente sentidas e mais notáveis. Assim, determina a atual CRFB.

Art. 225. Todos têm direito ao meio ambiente ecologicamente equilibrado, bem de uso comum do povo e essencial à sadia qualidade de vida, impondo-se ao Poder Público e à coletividade o dever de defendêlo e preservá-lo para as presentes e futuras gerações (BRASIL, CRFB/1988, art. 225).

O bem ambiental representado pelas cidades se mostra codificado, de maneira genérica, no caput do artigo 225 da CRFB de 1988 e dele se extraem os requisitos essenciais para que se possa de fato encaixá-las nas proteções existentes. Portela (2013), com base na atual CRFB expressa que o ambiente é o bem de uso comum do povo e é essencial à qualidade de vida da sociedade. O Estado, então, tem por obrigação preserválo para a sociedade que serve e que irá servir.

\section{A POLUIÇÃO VISUAL}

1 Tradução livre: "[...] uma grande população que se agrega em um local central com edifícios e monumentos que representam instituições que organizam e facilitam a produtividade". 
Para Fiorillo (2017) a poluição visual, assim como as outras formas de poluição descritas no artigo $3^{\circ}$, III, da Lei n 6.938/1981, degrada a qualidade de vida dos habitantes que estão no ambiente afetado por ela a ponto de terem sua saúde, segurança e bem-estar prejudicados, além de afetarem as condições estéticas do ambiente. Assim o artigo define:

Art. $3^{\circ}$ - Para os fins previstos nesta Lei, entende-se por:

$[\ldots]$

III - poluição, a degradação da qualidade ambiental resultante de atividades que direta ou indiretamente:

a) prejudiquem a saúde, a segurança e o bem-estar da população;

b) criem condições adversas às atividades sociais e econômicas;

c) afetem desfavoravelmente a biota;

d) afetem as condições estéticas ou sanitárias do meio ambiente;

e) lancem matérias ou energia em desacordo com os padrões ambientais estabelecidos; (BRASIL, Lei $n^{\circ}$ $6.938 / 1981$, art. $\left.3^{\circ}\right)$.

A poluição visual é gerada de forma paulatina e se espalha vagarosamente no ambiente visual das cidades (FIORILLO, 2017). Isto é especialmente evidente em metrópoles, nas quais é extrema a quantidade de peças publicitárias que confundem motoristas, ocultam o meio ambiente cultural, tutelado pela atual CRFB e são passíveis de igual proteção, além de causarem incômodo na já pressionada população existente nestes grandes centros populacionais. A esse respeito o artigo 216 da CRFB determina que

Art. 216. Constituem patrimônio cultural brasileiro os bens de natureza material e imaterial, tomados individualmente ou em conjunto, portadores de referência à identidade, à ação, à memória dos diferentes grupos formadores da sociedade brasileira, nos quais se incluem:

$[\ldots]$

II - os modos de criar, fazer e viver;

III - as criações científicas, artísticas e tecnológicas;

IV - as obras, objetos, documentos, edificações e demais espaços destinados às manifestações artísticoculturais;

V - os conjuntos urbanos e sítios de valor histórico, paisagístico, artístico, arqueológico, paleontológico, ecológico e científico.

$[\ldots]$

$\int 4^{\circ}$ Os danos e ameaças ao patrimônio cultural serão punidos, na forma da lei. (BRASIL, CRFB/1988, art. 226).

Determinados centros urbanos do mundo, como Paris, se tornaram palcos de fortes demonstrações anti-publicitárias. $\mathrm{O}$ aspecto antigo da ágora grega emulado pelos ambientes públicos, de expressão de diversidade de pensamentos e de debate público, se degenerou a partir da crescente mercantilização do aparato visual dos espaços de uso comum para a promoção de peças publicitárias que descaracterizam a cidade e a tornam visualmente desagradável, o que levou a uma forma peculiar de protesto, caracterizada por pichações críticas à poluição visual para Lamireau (2010)

Ces mouvements anti-publicitaires sont décrits par les auteurs - pour la plupart journalistes attentifs à l'évolution des mouvances contestataires sur le sol français - comme participant à l'émergence de «nouvelles » formes de protestation. Sous le titre explicite Les nouveaux militants, Laurent Jeanneau et Sébastien Lernould affirment ainsi que les actions anti-publicitaires sont menées par des personnes ayant fui les luttes politiques et syndicales traditionnelles pour s'engager sur des chemins plus " festifs ", provocateurs et trublions. De la même façon Sébastien Darsy, avec Le Temps de l'Anti Pub, inscrit les 
actions anti-publicitaires dans une tendance de «politisation des modes de vie » et une aspiration à de nouvelles valeurs, à une prise de conscience des méfaits de l'extension d'une communication commerciale dans l'espace public (LAMIREAU, 2010, p. 19).

$\mathrm{O}$ arquiteto urbanista dinamarquês Jan Gehl argumenta que um meio ambiente artificial bem cuidado, com atrações visuais amenas que consigam causar prazer aos seus habitantes é capaz de modificar os hábitos ao ar livre da população. A qualidade visual dos centros comerciais das cidades aumenta a circulação e utilização destes centros, além de provocar melhores impressões de todo o aparato urbano existente e impulsionar o aparecimento espontâneo de novas atividades coletivas nestes locais (PORTELLA, 2016).

Lembra-se que, antes de serem centros econômicos, as metrópoles se apresentam como cidades, e, por isto, têm por princípio oferecerem bem-estar e terem desenvolvidas as suas funções sociais, pelo que se depreende do artigo 182 da CRFB de 1988. A poluição visual atinge diretamente o direito fundamental do meio ambiente ecologicamente equilibrado, transparecido no art. 225 da CRFB (FIORILLO, 2017).

O impacto direto da publicidade e da propaganda na noção de poluição visual deve ser pesado por meio, inicialmente, da sua conceituação. A divulgação de informações pela mídia exterior pode ser dividida em três intenções principais: (1) a divulgação da marca, (2) a identificação do estabelecimento e (3) o reforço do lugar. A divulgação da marca, como VARGAS (2008) explicita que é

mais centrada nos outdoors, acontece fora do seu estabelecimento de origem e busca alta visibilidade por parte da população através da sua divulgação no espaço público. Tem como finalidade reforçar o uso de um tipo de produto e fixar a marca e, portanto, está mais associada ao setor de produção de bens e serviços, divulgando: produtos alimentares, bebidas, serviços de comunicação; dentre vários outros. Pode ainda divulgar estabelecimentos comerciais como grandes supermercados, shopping centers, lojas de departamentos; estabelecimentos bancários; promoções de shows; e, servir, ainda, para divulgar e promover realizações do poder público ou de cidades a visitar (VARGAS, 2008, s/p).

A identificação do estabelecimento, por sua vez, compõe a fachada da loja em questão. As placas indicativas do que se trata um estabelecimento comercial em específico e auxiliam na identificação do local, para Vargas (2008) entre estes estabelecimentos podem ser citados as "as farmácias, restaurantes, dentistas, clínicas e inclusive os próprios estacionamentos. Muitas vezes, a própria cor da edificação ou formato diferenciado funciona como um fator de rápida identificação" (VARGAS, 2008, s/p).

O reforço do lugar se caracteriza pelo agrupamento de estabelecimentos comerciais de lazer que não necessariamente precisam se diferenciar visualmente, mas apenas pelo público ou serviço oferecidos. Neste caso, a divulgação da marca é parte grande nesta diferenciação. "Nesta categoria podemos citar Times Square, Las Vegas, Vila Madalena em São Paulo, Quartier Latin em Paris, etc.” (VARGAS, 2008, s/p).

Esta divulgação, por estes meios, pode tornar saturado o ambiente, além de descaracterizá-lo de maneira a causar confusão. A saturação rouba dos habitantes o prazer da variedade ordenada e, por consequência, os dessensibiliza graças à aleatoriedade e desordem dos signos visuais apresentados. A qualidade visual dos espaços públicos influencia o comportamento humano, o tornando mais seguro e melhor capaz de provocar integração comunitária, entre a própria população e entre a população e as autoridades locais (PORTELLA, 2016).

Os sinais comerciais, como a divulgação das marcas, a identificação dos estabelecimentos e o reforço dos lugares (VARGAS, 2008) podem, mesmo quando encomendados pela administração municipal, prejudicar o caráter histórico dos centros mais antigos da cidade. Estes sinais, quando não se relacionam ao caráter histórico das áreas em que se encontram, afetam a percepção da população e sua avaliação destes espaços 
públicos. A essência local de uma determinada área pode ser muito prejudicada ao converter o espaço visual público em um produto de consumo.

\section{A LEI CIDADE LIMPA}

Em 26 de setembro de 2006 a Câmara Municipal de São Paulo aprovou o Projeto de Lei no 379/2006 e instituiu a Lei no 14.223/2006, que dispõe, como explicitado em sua ementa, "sobre a ordenação dos elementos que compõem a paisagem urbana do Município de São Paulo" (SÃO PAULO, Lei n 14.223/2006, Ementa). A Lei foi acompanhada pelo Decreto municipal $n^{\circ} 47.950$, de 5 de dezembro de 2006, que a regulamentou e dispõe sobre os pormenores da ordenação dos elementos que a Lei indica.

O conforto ambiental e os direitos fundamentais são elementos-chave exibidos já no primeiro capítulo da Lei, em seus artigos $3^{\circ}$ e $4^{\circ}$, a seguir expostos:

Art. $3^{\circ}$. Constituem objetivos da ordenação da paisagem do Município de São Paulo o atendimento ao interesse público em consonância com os direitos fundamentais da pessoa humana e as necessidades de conforto ambiental, com a melhoria da qualidade de vida urbana, assegurando, dentre outros, os seguintes:

I - o bem-estar estético, cultural e ambiental da população;

II - a segurança das edificações e da população;

III - a valorização do ambiente natural e construído;

IV - a segurança, a fluidez e o conforto nos deslocamentos de veículos e pedestres;

$\mathrm{V}$ - a percepção e a compreensão dos elementos referenciais da paisagem;

VI - a preservação da memória cultural;

VII - a preservação e a visualização das características peculiares dos logradouros e das fachadas;

VIII - a preservação e a visualização dos elementos naturais tomados em seu conjunto e em suas peculiaridades ambientais nativas;

IX - o fácil acesso e utilização das funções e serviços de interesse coletivo nas vias e logradouros;

$\mathrm{X}$ - o fácil e rápido acesso aos serviços de emergência, tais como bombeiros, ambulâncias e polícia;

XI - o equilíbrio de interesses dos diversos agentes atuantes na cidade para a promoção da melhoria da paisagem do Município.

Art. $4^{\circ}$. Constituem diretrizes a serem observadas na colocação dos elementos que compõem a paisagem urbana:

I - o livre acesso de pessoas e bens à infraestrutura urbana;

II - a priorização da sinalização de interesse público com vistas a não confundir motoristas na condução de veículos e garantir a livre e segura locomoção de pedestres;

III - o combate à poluição visual, bem como à degradação ambiental;

IV - a proteção, preservação e recuperação do patrimônio cultural, histórico, artístico, paisagístico, de consagração popular, bem como do meio ambiente natural ou construído da cidade;

V - a compatibilização das modalidades de anúncios com os locais onde possam ser veiculados, nos termos desta lei;

VI - a implantação de sistema de fiscalização efetivo, ágil, moderno, planejado e permanente (SÃO PAULO, Lei no $14.223 / 2006$, arts. $3^{\circ}$ e $4^{\circ}$ ).

A Lei ainda conceitua e divide o que considera “anúncio”, este é qualquer tipo de comunicação visual veiculada na paisagem visível de um logradouro público e que contenha estrutura e área de exposição. Ele pode ser de três tipos:

(1) O anúncio indicativo, que é a identificação do que o local se trata. Conforme exposto em item 
anterior, o anúncio indicativo é conceitualmente emparelhado com a identificação do estabelecimento;

(2) O anúncio publicitário, que serve para a exibição de publicidade e está instalado fora do local ao qual a publicidade em questão se refere;

(3) O anúncio especial, que a Lei explicita com mais detalhes em seu artigo 19:

Art. 19. Para os efeitos desta lei, os anúncios especiais são classificados em:

I - de finalidade cultural: quando for integrante de programa cultural, de plano de embelezamento da cidade ou alusivo a data de valor histórico, não podendo sua veiculação ser superior a 30 (trinta) dias, conforme decreto específico do Executivo, que definirá o projeto urbanístico próprio;

II - de finalidade educativa, informativa ou de orientação social, religiosa, de programas políticos ou ideológicos, em caso de plebiscitos ou referendos populares;

III - de finalidade eleitoral: quando destinado à propaganda de partidos políticos ou de seus candidatos, na forma prevista na legislação federal eleitoral;

IV - de finalidade imobiliária, quando for destinado à informação do público para aluguel ou venda de imóvel, não podendo sua área ultrapassar $1,00 \mathrm{~m}^{2}$ (um metro quadrado) e devendo estar contido dentro do lote.

$\int 1^{\circ}$. Nos anúncios de finalidade cultural e educativa, o espaço reservado para o patrocinador será determinado pelos órgãos municipais competentes.

$\int 2^{\circ}$. Os anúncios referentes à propaganda eleitoral deverão ser retirados no prazo máximo de 15 (quinze) dias, a contar da data da realização das eleições ou plebiscitos. (SÃO PAULO, Lei no 14.223/2006, art. 19).

A Lei procura modificar o foco da publicidade de grandes signos externos para o "mobiliário público", termo que se refere a elementos paisagísticos artificiais existentes no meio ambiente urbano. O artigo 22 da Lei em questão se utiliza de rol exemplificativo para descrevê-los, e exemplos que se podem encontrar na letra da Lei variam de cabines de segurança a abrigos de parada de transporte público de passageiros, além de totens indicativos, painéis eletrônicos, bicicletários e sanitários públicos.

A legislação adotada pela cidade de São Paulo é surpreendentemente restritiva. Enquanto se é comum que o tipo de desordem do uso da mídia exterior que leva à poluição visual urbana seja mais profundo em países em desenvolvimento a cidade conseguiu se diferenciar do tipo de legislação existente nos principais polos do planeta dado que é uma das maiores metrópoles do mundo, centro comercial extremamente importante do hemisfério sul, o que, pela própria exploração do comércio nestes ambientes, torna a adoção de leis restritivas mais complicada (CASARIN e SANTIAGO, 2013).

São Paulo começou a ter problemas de excesso de informação visual referente aos anúncios já na década de 1950. Em 1996 foi aprovada uma Lei que os regulava, embora de forma muito flexível, que foi alterada em 2003 e, depois, revogada em 2006 para dar lugar à atual Lei no 14.223/2006 (CASARIN e SANTIAGO, 2013). Drigo destaca o efeito que se passava na era anterior à Lei Cidade Limpa ao descrever uma análise do ambiente do Elevado João Goulart (então Elevado Costa e Silva), ao afirmar que

O olhar do usuário pode ser apanhado pelo Pet shop, pelo 'Jesuíno', pela tevê 'BRAVIA' ou pela 'mulher' na tevê, pelo carro, pelas placas de trânsito ou pelo semáforo. Há algumas casas, provavelmente habitadas, cujas janelas estão cobertas por anúncios publicitários. Se houver moradores, esses provavelmente resistem à invasão imobiliária verticalizante e, se lá residem, estão de olhos fechados, pois as placas roubam suas janelas (DRIGO, 2009, p. 58).

Casarin e Santiago (2013) defendem que a ideia que se busca na Lei Cidade Limpa é, a partir dela, controlar a sinalização urbana de modo a reduzir o seu teor desorientador e saturado. Políticas públicas se 
baseiam neste primeiro ente legislativo, derivado da atual CRFB e mais pormenorizado em nível municipal, mesmo que o município de São Paulo seja comparável a um pequeno país. Para que se salvaguarde a saúde pública frente aos impulsos mercadológicos que envolvem este tipo de situação.

\section{CONSIDERAÇÕES FINAIS}

Mais de dez anos já se passaram desde que a Lei Cidade Limpa começou a regular a paisagem urbana da cidade de São Paulo. O impacto imediato desta legislação regulatória foi a redescoberta da arquitetura e do ambiente urbano, antes ocultados pela confusão sensorial advinda do excesso de publicidade. Os signos naturais da cidade, suas ruas e construções, se reintroduziram no inconsciente coletivo durante esta última década.

Um ambiente mais equilibrado e limpo visualmente é, além de agradável ao olhar, mais saudável mentalmente para a população residente e passageira. Um centro comercial, social e industrial grande quanto a cidade de São Paulo, lar de quase 6\% da população de todo o país, se mostra um exemplo muito grande a limitar, não apenas em áreas históricas, mas em todo o perímetro municipal a poluição visual advinda do excesso de informação.

Ao reclamar de volta a cidade a seus cidadãos a Lei Cidade Limpa conseguiu atingir, embora ainda de forma incompleta, um dos requisitos para a salvaguarda do meio ambiente artificial urbano. Tal meio ambiente, habitat típico da espécie humana desde a segunda metade do último século é objeto de proteção constitucional.

A sociedade, especificamente, a pessoa humana é o ponto de maior proteção da atual CRFB. Esta se baseia na proteção individual e na salvaguarda social da coletividade de forma harmônica com as intenções de produção capitalista, e, por isso, protege todo o modo de vida da sociedade humana com vários direitos fundamentais.

A vida em uma cidade limpa, termo usado de maneira ampla, se relacionando tanto à limpeza urbana como saneamento básico, ar atmosférico, segurança pública e poluição visual e é um direito fundamental dos indivíduos que constituem a sociedade e, a Lei no 14.223/2006 se compromete a garantir este direito da forma referente à prevenção à poluição visual, um tipo de poluição nem sempre visto, dadas as suas particularidades.

O que se pode ver, ao fim, é uma ideia para o ressurgimento da publicidade dentro do espaço urbano, de forma tanto ditada na própria Lei, por meio do uso do chamado mobiliário urbano, quanto de maneiras mais sutis, menos prejudiciais às idiossincrasias de cada cidade e à existência de seus moradores.

\section{REFERÊNCIAS}

BRASIL. Constituição da República Federativa do Brasil. Brasília: Supremo Tribunal Federal, Secretaria de Documentação, 2017. Disponível em: <http://www.stf.jus.br/arquivo/cms/legislacaoConstituicao/anexo/CF.pdf>. Acesso em: 20 jun. 2018.

. Lei № 6.938, de 31 de agosto de 1981. Dispõe sobre a Política Nacional do Meio Ambiente, seus fins e mecanismos de formulação e aplicação, e dá outras providências. Disponível em :< http://www.planalto.gov.br/ccivil_03/Leis/L6938compilada.htm>. Acesso em: 22 jun. 2018.

CASARIN, Vanessa; GONÇALVES SANTIAGO, Alina. Primeiras aproximações críticas às políticas de controle de anúncios na paisagem urbana: o caso de São Paulo. Oculum Ensaios, vol. 10, núm. 1, 
jan-jun, 2013, pp. 43-55. Pontifícia Universidade Católica de Campinas. Campinas, Brasil. Disponível em: <http://periodicos.puc-campinas.edu.br/seer/index.php/oculum/article/view/1926>. Acesso em: 21 jun. 2018.

DRIGO, Maria Ogécia. Cidade/invisibilidade e cidade/estranhamento: São Paulo antes e depois da lei "Cidade Limpa". Revista Galáxia, São Paulo, n. 17, p. 49-64, jun. 2009. Disponível em: <https://revistas.pucsp.br/index.php/galaxia/article/view/2097>. Acesso em: 10 jun. 2018.

ELMQVIST T.; REDMAN C.L.; BARTHEL S.; COSTANZA R. History of Urbanization and the Missing Ecology. In: ELMQVIST T. et al. (org.), Urbanization, Biodiversity and Ecosystem Services: Challenges and Opportunities. Dordrecht: Springer, 2013.

FIORILLO, Celso Antonio Pacheco. Curso de direito ambiental brasileiro. São Paulo: Saraiva, 2017. IBGE. Diretoria de Pesquisas, Coordenação de População e Indicadores Sociais. Estimativas da população residente em 2018. Disponível em: <https://cidades.ibge.gov.br>. Acesso em: 20 set. 2018.

LAMIREAU, Clara. "Haro sur l'affichage ! " Agir par écrit contre la publicité dans l'espace public parisien. Quaderni, N. 72, 2010. Disponível em: <http://journals.openedition.org/quaderni/477>. Acesso em: 28 jun. 2018.

PORTELLA, Adriana. Visual pollution: advertising, signage and environmental quality. Londres: Routledge, 2016.

PORTELA, Márcio Oliveira. Meio ambiente e paisagem urbana: publicidade e propaganda externas e poluição visual. Revista Direito Ambiental e sociedade, v. 3, n. 2, 2013, p. 135-151.

SANTAMOURIS, Matheos. On the built environment - the urban influence in: SANTAMOURIS, Matheos (Ed.). Energy and climate in the urban built environment. Nova lorque: Routledge, 2013.

SÃO PAULO. Lei Municipal $n^{\circ} 14.233$, de 26 de setembro de 2006. Dispõe sobre a ordenação dos elementos que compõem a paisagem urbana do Município de São Paulo. Disponível em: <http://www.prefeitura.sp.gov.br/cidadelimpa/>. Acesso em: 20 jun. 2018.

VARGAS, Heliana Comin. Limites ao controle da publicidade na paisagem urbana. Ambiente Já, Porto Alegre, v. 8, n. 2213, 2007. Disponivel em: <http://www.fau.usp.br/depprojeto/labcom/produtos/2007_vargas_poluicaovisual.pdf>. Acesso em: 24 jun. 2018. 